\title{
The Chemical Bond between Transition Metals and Oxygen: Electronegativity, d-Orbital Effects, and Oxophilicity as Descriptors of Metal-Oxygen Interactions
}

\author{
Moltved, Klaus A.; Kepp, Kasper Planeta
}

Published in:

Journal of Physical Chemistry C

Link to article, DOI:

10.1021/acs.jpcc.9b04317

Publication date:

2019

Document Version

Peer reviewed version

Link back to DTU Orbit

Citation (APA):

Moltved, K. A., \& Kepp, K. P. (2019). The Chemical Bond between Transition Metals and Oxygen:

Electronegativity, d-Orbital Effects, and Oxophilicity as Descriptors of Metal-Oxygen Interactions. Journal of Physical Chemistry C, 123(30), 18432-18444. https://doi.org/10.1021/acs.jpcc.9b04317

\section{General rights}

Copyright and moral rights for the publications made accessible in the public portal are retained by the authors and/or other copyright owners and it is a condition of accessing publications that users recognise and abide by the legal requirements associated with these rights.

- Users may download and print one copy of any publication from the public portal for the purpose of private study or research.

- You may not further distribute the material or use it for any profit-making activity or commercial gain

- You may freely distribute the URL identifying the publication in the public portal 


\title{
C: Surfaces, Interfaces, Porous Materials, and Catalysis
}

Subscriber access provided by DTU Library

\section{The Chemical Bond between Transition Metals and Oxygen: Electronegativity, d-Orbital Effects, and Oxophilicity as Descriptors of Metal-Oxygen Interactions}

\author{
Klaus August Moltved, and Kasper P. Kepp
}

J. Phys. Chem. C, Just Accepted Manuscript • DOI: 10.1021/acs.jpcc.9b04317 • Publication Date (Web): 08 Jul 2019

Downloaded from pubs.acs.org on July 14, 2019

\section{Just Accepted}

"Just Accepted" manuscripts have been peer-reviewed and accepted for publication. They are posted online prior to technical editing, formatting for publication and author proofing. The American Chemical Society provides "Just Accepted" as a service to the research community to expedite the dissemination of scientific material as soon as possible after acceptance. "Just Accepted" manuscripts appear in full in PDF format accompanied by an HTML abstract. "Just Accepted" manuscripts have been fully peer reviewed, but should not be considered the official version of record. They are citable by the Digital Object Identifier (DOI®). "Just Accepted" is an optional service offered to authors. Therefore, the "Just Accepted" Web site may not include all articles that will be published in the journal. After a manuscript is technically edited and formatted, it will be removed from the "Just Accepted" Web site and published as an ASAP article. Note that technical editing may introduce minor changes to the manuscript text and/or graphics which could affect content, and all legal disclaimers and ethical guidelines that apply to the journal pertain. ACS cannot be held responsible for errors or consequences arising from the use of information contained in these "Just Accepted" manuscripts. 
The Chemical Bond between Transition Metals and Oxygen: Electronegativity, d-Orbital Effects, and Oxophilicity as Descriptors of Metal-Oxygen Interactions

Klaus A. Moltved and Kasper P. Kepp*

Technical University of Denmark, DTU Chemistry, Building 206, 2800 Kgs. Lyngby, DK Denmark.

* Corresponding author: Phone: +045 452524 09. E-mail: kpj@,kemi.dtu.dk 


\begin{abstract}
The chemical bonds between a transition metal $(\mathrm{M})$ and oxygen $(\mathrm{O})$ are of major importance in catalysis, mineralogy, biology and astrophysics, and adequate theoretical description of these bonds is thus highly needed. This paper establishes that, despite recent debate on its accuracy for transition metal systems, $\operatorname{CCSD}(\mathrm{T})$ is an excellent benchmark standard for transition metal oxide interactions, with errors approaching those of experiment. We conclude this from a study of all $60 \mathrm{M}-\mathrm{O}$ and $\mathrm{M}^{+}-\mathrm{O}$ BDEs of the $3 \mathrm{~d}, 4 \mathrm{~d}$, and $5 \mathrm{~d}$ metals, constituting a balanced dataset in terms of $\mathrm{d}^{\mathrm{q}}$ configurations that also enable an assessment of the trend chemistry in oxygen's ability to bind to transition metals. The BDEs decrease towards the right of the transition metal series, with humps at groups 4-5 and 8-9. The linear trend follows the increasing electronegativity when going from the left to the right, whereas the humps are caused by differential occupation of bonding $\delta$-orbitals and antibonding $\pi$-orbitals. We show that the BDEs correlate strongly with oxophilicity and energies of metal surface chemisorption $\left(\mathrm{R}^{2}=0.81-0.89\right)$, i.e. the local M-O bond dominates the energetics of transition metals reacting with oxygen. Therefore, theoretical studies of oxygen-involving transition metal chemistry should emphasize the accuracy of the local M-O bonds. A "bottom-up" approach to theoretical catalysis may thus produce more accurate trend predictions of relevance to e.g. catalyst design. Finally, our analysis explains the large differences in chemisorption of oxygen on metal surfaces as primarily caused by the metal electronegativity relative to oxygen, defining the strength of the polar covalent bonding, and secondarily to d-orbital net bonding.
\end{abstract}




\section{Introduction}

The chemical bond between a transition metal and oxygen (M-O) plays a central role in many important chemical processes, e.g. catalytic water splitting and conversion of methane to methanol, and many catalytic processes involving oxygen reduction. ${ }^{1-4}$ In the mineral world, the main ores of a large number of metals are in the form of oxides held together by M-O bonds, and metal oxides have very many useful technological applications. ${ }^{5-8}$ In biology, many enzymes utilize the bonding of oxygen to transition metals such as copper or iron to activate the O-O bond for further reactions. $^{9-11}$ The simple diatomic $\mathrm{M}-\mathrm{O}$ systems are very important in astrochemistry, hightemperature inorganic chemistry and in order to understand transition metal spectroscopy and bonding more fundamentally. ${ }^{12}$ In particularly, the intense current interest in increasingly small catalyst systems, with highly effective single-atom catalysts as the ultimate limit, puts a renewed focus on understanding single-metal atom ligand interactions as the minimal catalytic unit ${ }^{13,14}$.

The M-O bond in its pure form describes the tendency of a metal to bind to oxygen, without any modulating effects of other metals or ligands. Understanding the intrinsic tendency of metals to associate with oxygen is an important starting point for understanding the role of the metal in many reactions, as presented mainly by the metal's oxophilicity. ${ }^{15}$ The fact that this simple, generic tendency explains both ore composition and chemical reactions of much more complicated systems ${ }^{15}$ indicates that the local M-O bond dominates the energetics and thus trend chemistry of real systems relative to the modulating atoms. Many studies use approximate density functional methods to study catalysis on metal surfaces. ${ }^{16,17}$ These studies tacitly assume that the modulating catalyst effects are more important to describe with a low-accuracy methods than it is to describe the directly involved chemical bonds at high accuracy, and thus some accuracy in the M-O bonds (and other bonds) is sacrificed to study a larger catalytic system. It is of both fundamental and practical interest to understand the relative importance to the trend chemistry of the local M-O 
bond and the modulating effects of the remaining catalyst. Furthermore, the main features that drive trends in $\mathrm{M}-\mathrm{O}$ bonding, i.e. electronegativity vs. d-orbital effects, need to be quantified.

To understand the electronic structure of the $\mathrm{M}-\mathrm{O}$ bond in detail, we studied in completeness all the 30 neutral MO molecules and the 30 cationic $\mathrm{MO}^{+}$systems of the $3 \mathrm{~d}$, $4 \mathrm{~d}$, and $5 \mathrm{~d}$ transition series that define the intrinsic bonding of d-transition metals to oxygen and for which experimental bond dissociation enthalpies (BDEs) are available in most cases. ${ }^{18}$ The 60 diatomic systems constitute a balanced data set that allows us to assess the M-O bonding systematically across all electronic configurations of the $3 \mathrm{~d}, 4 \mathrm{~d}$, and $5 \mathrm{~d}$ transition series. Balanced data sets avoid the risk of conclusions being system-dependent and biased by over-represented $\mathrm{d}^{\mathrm{q}}$ electronic configurations or ligand types. ${ }^{19,20}$

Given their importance to inorganic chemistry and catalysis, there is an ongoing debate on the accuracy of both experimental and computed BDEs for metal-ligand (M-L) bonds ${ }^{19-26}$. Both experiments and computations suffer much larger uncertainties for M-L bonds than for bonds composed only of organic chemistry elements of the p-block; some of the uncertainty relates to close-lying electronic configurations in the d-block. The accuracy of the "golden standard" $\operatorname{CCSD}(\mathrm{T})$ has received considerable recent focus in terms of its accuracy for transition metal chemistry, with various views in the debate. ${ }^{22-24,27}$ Methods that account explicitly for static correlation (e.g. CASPT2 ${ }^{28}$ ) are in principle suited for transition metals systems but are ambiguous in their choice of active spaces preventing systematic use for many compounds and carry biases from the HF reference causing excessive spin polarization, which makes them somewhat spinunbalanced. ${ }^{29-31}$ Instead, we show that $\operatorname{CCSD}(\mathrm{T})$ is a golden standard for the M-O bonds with accuracy approaching that of experiment. Thus, coupled-cluster theory, aided by developments enabling the study of larger systems, ${ }^{32}$ can adequately guide the choice and development of density functionals for d-transition metal-oxygen chemistry when experimental data are scarce. 
Previous studies, $5,19,39,40,22,23,33-38$ have considered some of the 60 diatomic systems at various levels of theory but there is no previous study of all the 60 transition metal oxides and the associated trend chemistry deduced from $\operatorname{CCSD}(\mathrm{T})$. In particular, van Santen and Tranca have studied many of these systems using DFT with a similar aim to understand trend chemistry of metal-ligand binding ${ }^{40}$.

\section{Methods}

We used the Turbomole software, version $7.0^{41}$ for all computations in this work. We applied the resolution of identity approximation ${ }^{42}$ to speed up calculations. The BDEs were calculated for all the 30 neutral $\mathrm{M}-\mathrm{O}$ and 30 cationic $\mathrm{M}^{+}-\mathrm{O}$ systems of the $3 \mathrm{~d}, 4 \mathrm{~d}$ and $5 \mathrm{~d}$ transition metals.

Geometry optimizations. Geometries were optimized for the 60 diatomic systems using the BP $86^{43,44}$ functional and the def2-TZVPP 45 basis, with energy convergence set to $10^{-6}$ au. The computed bond lengths are compiled in Table S1. For 14 of these systems experimental bond lengths are available as shown in Table S2. The average signed error in the computed bond lengths was $0.003 \AA$ and the mean absolute error (MAE) was $0.02 \AA$. This agrees well with the commonly cited $0.02 \AA$ average uncertainty in M-L bonds using this geometry optimization protocol, with other density functionals giving larger errors. ${ }^{46}$ The excellent agreement between CCSD(T)computed and experimental BDEs using these geometries as input gives us further reassurance that the employed geometries are adequate.

Single point energies. Single point energies were computed using $\operatorname{CCSD}(\mathrm{T})$ from a converged HF reference state, using a density and energy convergence of $10^{-7} \mathrm{au}$. For the singlepoint energies the def2-QZVPPD ${ }^{45}$ basis set was used for the metals ( $\mathrm{Sc}-\mathrm{Zn}, \mathrm{Y}-\mathrm{Cd}$ and $\mathrm{La}-\mathrm{Hg}$ ) and aug-cc-pV5Z47 with diffuse basis functions was used for oxygen because it is very electronegative and thus harbors a large surplus of negative net charge, causing a looser electron 
density at the oxygen atom. This basis set in combination with $\operatorname{CCSD}(\mathrm{T})$ is close to the basis set limit, as seen from the fact that this protocol gives chemical accuracy $(<4 \mathrm{~kJ} / \mathrm{mol}$ errors $)$ for the strong p-block element bonds such as $\mathrm{C}-\mathrm{O}, \mathrm{O}-\mathrm{O}$, and $\mathrm{N}-\mathrm{N}$, where experimental errors are much smaller and chemical accuracy can thus be confirmed positively. ${ }^{48}$

Spin states. Identifying the correct HF reference with lowest-possible energy after final calculation is critical to all post-HF methods including $\operatorname{CCSD}(\mathrm{T})$. To determine the spin states of lowest energy, single point energy calculations were performed for the spin states predicted by experiment compiled in Table $\mathbf{S 3}$ and states of $M_{\mathrm{S}} \pm 1$ ( -1 only if $M_{\mathrm{S}}$ was 1 or higher). For systems with unknown spin state, single point energy $\operatorname{CCSD}(\mathrm{T})$ calculations for the spin states predicted from the geometry calculations and all states of $M_{\mathrm{S}} \pm 1$ were performed on the fully geometry optimized spin states. Table $\mathbf{S} 4$ summarizes the spin multiplicity predicted by CCSD(T). By comparing Table S3 and Table S4 it can be seen that CCSD $(\mathrm{T})$ predicts the experimental spin state in 31 of the 33 cases were experimental spin states are available. The two exceptions are $\mathrm{ZrO}$ and $\mathrm{HfO}^{+}$. For $\mathrm{ZrO}$ it has already been noted that the energy difference between the assigned ground state of ${ }^{\mathbf{1}} \boldsymbol{\Sigma}^{+}$and the ${ }^{3} \boldsymbol{\Delta}$ state is very small $(\approx 13 \mathrm{~kJ} / \mathrm{mol})^{5}$. The $\operatorname{CCSD}(\mathrm{T})$ energy of the triplet state was $22 \mathrm{~kJ} / \mathrm{mol}$ lower in energy than the singlet. Since the two reported experimental BDE values are $766 \mathrm{~kJ} / \mathrm{mol}$ and $801 \mathrm{~kJ} / \mathrm{mol}$ this will not affect the accuracy very much even in this special case. For $\mathrm{HfO}^{+}$the experimentally predicted ground state is ${ }^{\mathbf{4}} \boldsymbol{\Sigma}^{-}$, but $\mathrm{CCSD}(\mathrm{T})$ predicts a doublet ground state to be $426 \mathrm{~kJ} / \mathrm{mol}$ lower in energy than the state with spin multiplicity four. The $\operatorname{CSSD}(\mathrm{T})$ method however predicts the BDE with an error of $21 \mathrm{~kJ} / \mathrm{mol}$ using this energy and we are thus confident that our doublet state for $\mathrm{HfO}^{+}$is close to the real energy even if we cannot rule out a close-lying alternative state.

In four systems CCSD(T) identified another spin state within $20 \mathrm{~kJ} / \mathrm{mol}$ of the ground state as summarized in Table S5. For these systems, there is some uncertainty about the assignment of 
the spin state, but the effect on the calculated BDEs is maximally $19 \mathrm{~kJ} / \mathrm{mol}$ and thus a potential error in these four systems has a worst-possible effect on our trends and error analysis of $\sim 1 \mathrm{~kJ} / \mathrm{mol}$.

Table S6 shows the experimental spin states from NIST ${ }^{49}$ used in the calculation of the energy of atoms and ions of the transition metals. Adequate convergence to the established ground states was ensured by using "spin annealing", i.e. starting single point energy calculations from higher spin multiplicities than the ground state (for most systems $M_{\mathrm{S}}+2$ ) and decreasing the spin multiplicity in steps of 2. Calculations started directly from the expected spin state frequently leads to meta-stable configurations that are not completely spin polarized, because of very approximate start orbitals and thus we find that spin annealing is generally required when studying diverse transition metal systems.

Zero-point vibrational and relativistic corrections to the electronic energies. Zero point energies (ZPE) were computed from frequency analysis using the optimized geometry and the same level of theory as used for geometry optimizations, as summarized in Table S7. Scalarrelativistic effects of the $3 \mathrm{~d}$ transition metal oxides were estimated using the sum of the Darwin term and the expectation value of $P^{4}$ from a B3LYP single point energy calculation; the BDE corrections computed in this way can be seen in Table S8. The scalar-relativistic effects of the $4 \mathrm{~d}$ and $5 \mathrm{~d}$ transition metal oxides were estimated by using effective core potentials. The influence of spin-orbit coupling (SOC) was estimated by a Douglas-Kroll-Hess ${ }^{50,51}$ B3LYP energy calculation of 4th order for the $3 \mathrm{~d}$ metal oxides using the dhf-QZVPP-2c basis set. ${ }^{52}$ For the $4 \mathrm{~d}$ and $5 \mathrm{~d}$ metal oxides the effect of SOC was estimated by a two-component calculation including ECP calling the Turbomole keyword soghf with the dhf-QZVPP-2c basis set. The SOC corrections to the BDE are available in Table S9. This treatment of the SOC is somewhat unbalanced probably overestimating the effect for the SOC for the $3 \mathrm{~d}$ metals and slightly underestimating the SOC for the $4 \mathrm{~d}$ and $5 \mathrm{~d}$ 
metals. ${ }^{50,51}$ For some heavy metals the SOC correction to the BDE reaches $30 \mathrm{~kJ} / \mathrm{mol}$ (largest for $\mathrm{AuO}^{+}: 34.1 \mathrm{~kJ} / \mathrm{mol}$ ) but mostly it is below $10 \mathrm{~kJ} / \mathrm{mol}$.

Calculation of BDEs and errors. The BDEs of the $\mathrm{MO}$ and $\mathrm{MO}^{+}$molecules were calculated according to Equation 1:

$$
B D E(M-O)=E(M)+E(O)-E(M O)-E_{Z P E}+E_{\text {scalar }}+E_{S O C}+3.7 \mathrm{~kJ} / \mathrm{mol}
$$

$E(M), E(O)$ and $E(M O)$ are the single point energies of the metal, $\mathrm{O}$ and $\mathrm{MO}$ or $\mathrm{MO}^{+}$molecule, and are available in Tables S10-S11. $E_{Z P E}$ is the computed zero-point energy of the molecule. $E_{\text {scalar }}$ is the scalar relativistic energy correction, and $E_{S O C}$ is the computed SOC correction, and $3.7 \mathrm{~kJ} / \mathrm{mol}$ corresponds to $3 / 2 \mathrm{RT}$ at $298 \mathrm{~K}$ which is used to convert the BDE from $0 \mathrm{~K}$ to $298 \mathrm{~K}$. The 60 BDEs calculated for HF, MP2, CCSD and CCSD(T) are compiled in Table S12.

The signed errors (SE) discussed in this work were calculated according to Equation 2:

$$
S E=B D E(M O)_{\text {comput }}-B D E(M O)_{\exp }
$$

$B D E(M O)_{\text {comput }}$ are the BDEs calculated from Equation 1, and $B D E(M O)_{\text {exp }}$ are the experimental BDE. The absolute errors (AE) reported in this work is the absolute value of Equation 2, the mean signed errors (MSE) and mean absolute errors (MAE) discussed below are the means of the SE and $\mathrm{AE}$, respectively.

Experimental data. For 29 of the neutral M-O systems and 28 of the cationic $\mathrm{M}^{+}-\mathrm{O}$ systems, experimental BDEs were available from the CRC Comprehensive Handbook of Chemical Bond Energies ${ }^{18}$ and from additional literature, sometimes with multiple values for the same bond that can vary significantly. All the BDEs found are compiled in Table S13, with reported experimental errors. The recommended values of the CRC Comprehensive Handbook of Chemical Bond Energies ${ }^{18}$ are highlighted in green in Table S13. In cases with no recommended value, the 
value with the smallest uncertainty and best trend agreement was selected, giving the data set in Table S14. Subsequently, a few problematic cases discussed below were curated by choosing the alternative experimental numbers reflecting a consistent trend chemistry as seen in Figure S1 showing the variation of the BDE vs. period for neutral or cationic oxides, for the default experimental values of Table S14 and for the $\operatorname{CCSD}(\mathrm{T})$ computed values. According to this trend analysis, the final recommended experimental data used for all analysis can be seen in Table $\mathbf{1}$.

Table 1. Experimental BDEs at $298 \mathrm{~K}(\mathrm{~kJ} / \mathrm{mol})$ used in this work. Data are from the CRC Comprehensive Handbook of Chemical Bond Energies ${ }^{18}$ except three cases with reference and bold font. \pm indicates the reported experimental uncertainty. ? indicates no reported uncertainty.

\begin{tabular}{|c|c|c|c|c|c|c|c|c|c|}
\hline $\mathrm{ScO}$ & TiO & VO & $\mathrm{CrO}$ & MnO & $\mathrm{FeO}$ & $\mathrm{CoO}$ & NiO & $\mathrm{CuO}$ & $\mathrm{ZnO}$ \\
\hline $671 \pm 1$ & $667 \pm 6$ & $637 \pm ?$ & $461 \pm 9$ & $362 \pm 25$ & $407 \pm 1$ & $397 \pm 9$ & $366 \pm 30$ & $287 \pm 12$ & $159 \pm 4$ \\
\hline YO & $\mathrm{ZrO}$ & NbO & МоO & TcO & RuO & RhO & PdO & AgO & $\mathrm{CdO}$ \\
\hline $714 \pm 10$ & $766 \pm 11$ & $727 \pm 10$ & $525 \pm 4$ & $548 \pm ?$ & $528 \pm 42$ & $405 \pm 42$ & $238 \pm 13$ & $221 \pm 21$ & $98^{53} \pm 4$ \\
\hline LaO & HfO & $\mathrm{TaO}$ & WO & ReO & OsO & IrO & PtO & $\mathrm{AuO}$ & HgO \\
\hline $798 \pm ?$ & $801 \pm 13$ & $839 \pm ?$ & $720 \pm 71$ & NA & $575 \pm ?$ & $414 \pm 42$ & $391 \pm 42$ & $223 \pm 21$ & NA \\
\hline $\mathrm{ScO}^{+}$ & $\mathrm{TiO}^{+}$ & $\mathrm{VO}^{+}$ & $\mathrm{CrO}^{+}$ & $\mathrm{MnO}^{+}$ & $\mathrm{FeO}^{+}$ & $\mathrm{CoO}^{+}$ & $\mathrm{NiO}^{+}$ & $\mathrm{CuO}^{+}$ & $\mathrm{ZnO}^{+}$ \\
\hline $689 \pm 5$ & $667 \pm 7$ & $582 \pm 10$ & $359 \pm ?$ & $285 \pm 13$ & $343 \pm 2$ & $317 \pm 5$ & $192 \pm 10$ & $134 \pm 12$ & $161 \pm 5$ \\
\hline $\mathrm{YO}^{+}$ & $\mathrm{ZrO}^{+}$ & $\mathrm{NbO}^{+}$ & $\mathrm{MoO}^{+}$ & $\mathrm{TcO}^{+}$ & $\mathrm{RuO}^{+}$ & $\mathrm{RhO}^{+}$ & $\mathrm{PdO}^{+}$ & $\mathrm{AgO}^{+}$ & $\mathrm{CdO}^{+}$ \\
\hline $718 \pm 25$ & $753 \pm 11$ & $688 \pm 11$ & $488 \pm 2$ & NA & $372 \pm 5$ & $295 \pm 6$ & $145 \pm 11$ & $123 \pm 5$ & NA \\
\hline $\mathbf{L a O}^{+}$ & $\mathrm{HfO}^{+}$ & $\mathrm{TaO}^{+}$ & $\mathbf{W O}^{+}$ & $\mathbf{R e O}^{+}$ & $\mathrm{OsO}^{+}$ & $\mathrm{IrO}^{+}$ & $\mathrm{PtO}^{+}$ & $\mathrm{AuO}^{+}$ & $\mathrm{HgO}^{+}$ \\
\hline $851 \pm 15$ & $724 \pm 21$ & $761 \pm ?$ & $695 \pm 42$ & $435 \pm 59$ & $418 \pm 50$ & $411^{54} \pm 9$ & $318 \pm 7$ & $112^{54} \pm 8$ & NA \\
\hline
\end{tabular}

The most notable anomalies in the trend chemistry for the experimental data of Table S14 occur for $\mathrm{NiO}^{+}, \mathrm{CdO}, \mathrm{ReO}, \mathrm{HgO}, \mathrm{LaO}^{+}$and $\mathrm{IrO}^{+}$. Not surprisingly, these six species also exhibit very large errors compared to $\operatorname{CCSD}(\mathrm{T})$ when compared to the remaining data set. The recommended ${ }^{18}$ experimental value of $276 \mathrm{~kJ} / \mathrm{mol}$ for $\mathrm{NiO}^{+}$deviates significantly from the 
$\operatorname{CCSD}(\mathrm{T})$ computed value of $153 \mathrm{~kJ} / \mathrm{mol}$. The availability of an alternative experimental value of $192 \mathrm{~kJ} / \mathrm{mol}^{18,55}$ with a reported uncertainty of $10 \mathrm{~kJ} / \mathrm{mol}$ shows that one experimental number must be wrong. Both from Figure S1 and from the general agreement with experiment in other cases, the value of $192 \mathrm{~kJ} / \mathrm{mol}$ seems to be the most accurate experimental value and was thus used for $\mathrm{NiO}^{+}$in our dataset (Table 1).

The experimental $\mathrm{BDE}$ values of $\mathrm{CdO}$ and $\mathrm{HgO}$ also deviate significantly from the CCSD(T) computed value by 143 and $233 \mathrm{~kJ} / \mathrm{mol}$, respectively. For $\mathrm{ZnO}$, a decrease of $137 \mathrm{~kJ} / \mathrm{mol}$ in the $\mathrm{BDE}$ compared to $\mathrm{CuO}$ is observed. This would indicate that a decrease when going from group 11 to 12 could be expected as also predicted by the computed values for $\mathrm{CdO}$ and $\mathrm{HgO}$. $\mathrm{An}$ alternative experimental value of $\mathrm{CdO}$ of $98 \mathrm{~kJ} / \mathrm{mol}^{53}$ (reported uncertainty of $4 \mathrm{~kJ} / \mathrm{mol}$ ) is in agreement with this trend. For $\mathrm{HgO}$ no alternative experimental values could be found, and the predicted $\operatorname{CCSD}(\mathrm{T})$ value of $36 \mathrm{~kJ} / \mathrm{mol}$ also seems low. It would thus appear that for both experiment and computations, the BDEs of group-12 metal oxides are particularly challenging, as has already been established for $\mathrm{ZnO}$ previously ${ }^{19,22}$ and seen in other DFT calculations. ${ }^{56}$ Because of the required trend consistency, the value of $\mathrm{CdO}$ of $98 \mathrm{~kJ} / \mathrm{mol}$ was used and the value of $\mathrm{HgO}$ was not used.

For ReO there is a discrepancy between experiment and $\operatorname{CCSD}(\mathrm{T})$ of $119 \mathrm{~kJ} / \mathrm{mol}$. The reported experimental uncertainty is $84 \mathrm{~kJ} / \mathrm{mol}$, showing that the value is not precise. The experimental trends of Figure S1 further indicate that the BDE of ReO should be lower than the reported $627 \mathrm{~kJ} / \mathrm{mol}$. Since no alternative value for $\mathrm{ReO}$ could be found, it was excluded from the data set due to the very large uncertainty and lack of trend consistency.

The value of 875 for $\mathrm{LaO}^{+}$is high compared to the values of $\mathrm{HfO}^{+}$and $\mathrm{TaO}^{+}$when looking at the trend for the other early transition metal oxides (Figures S1A-S1E). Since there was an alternative value of $851 \mathrm{~kJ} / \mathrm{mol}$ with a lower reported experimental uncertainty ${ }^{18,55}$ we chose to use the value of $851 \mathrm{~kJ} / \mathrm{mol}$. Finally, Figure S1F shows a sudden drop in the BDE for $\mathrm{IrO}^{+}$ 
compared to experimental values of $\mathrm{OsO}^{+}$and $\mathrm{PtO}^{+}$. The reported experimental BDE of $247 \mathrm{~kJ} / \mathrm{mol}$ (with no reported uncertainty) is significantly lower by $171 \mathrm{~kJ} / \mathrm{mol}$ compared to the neighboring $\mathrm{OsO}^{+}$. Since an alternative value of $411 \mathrm{~kJ} / \mathrm{mol}^{54}$ with a good reported uncertainty of $9 \mathrm{~kJ} / \mathrm{mol}$ is available in much better agreement with the experimental trends of Figures S1A-S1E, this value for $\mathrm{IrO}^{+}$of $411 \mathrm{~kJ} / \mathrm{mol}$ was used as our recommended experimental data point. 


\section{Results and Discussion}

\section{Accuracy and precision of CCSD(T) for M-O bonds}

Table 2 summarizes the accuracy of $\operatorname{CCSD}(\mathrm{T})$ and CCSD for comparison, using our recommended experimental data set in Table 1. CCSD(T) has an overall MAE of $24.8 \mathrm{~kJ} / \mathrm{mol}$ and a MSE of 3.0 $\mathrm{kJ} / \mathrm{mol}$. The MAE of $24.8 \mathrm{~kJ} / \mathrm{mol}$ is far from "chemical accuracy" of $4 \mathrm{~kJ} / \mathrm{mol}$, while the MSE is within this range. However, the average reported error in the experimental numbers is $17 \mathrm{~kJ} / \mathrm{mol}$, and thus a perfect method is expected to have an MAE of perhaps $\sim 20 \mathrm{~kJ} / \mathrm{mol}$, considering the relativistic and vibrational approximations. The small MSE shows that the systematic error of $\operatorname{CCSD}(\mathrm{T})$ towards over-binding or under-binding is nearly zero. The MAE is also small considering that the absolute BDEs vary from approximately 100 to $800 \mathrm{~kJ} / \mathrm{mol}$, and thus the trend chemistry will be excellent, as confirmed below.

An important issue is not just the accuracy (MAE and MSE) but also the precision. We measure the precision of a method by the standard deviation of its error. This standard deviation is $31.5 \mathrm{~kJ} / \mathrm{mol}$ for $\operatorname{CCSD}(\mathrm{T})$ indicating that the $\mathrm{BDE}$ computed by $\operatorname{CCSD}(\mathrm{T})$ can be expected to vary by this amount from the experimental number in a majority of the cases if the data are normally distributed (between -60 and $+66 \mathrm{~kJ} / \mathrm{mol}$ for the $95 \%$ confidence interval). The largest errors found for the 60 systems are $+63.7 \mathrm{~kJ} / \mathrm{mol}$ and $-75.5 \mathrm{~kJ} / \mathrm{mol}$, respectively. While these results seem discouraging, they are significantly better than for $\mathrm{M}-\mathrm{H}$ bonds which are particularly challenging. ${ }^{20,57}$ In light of the experimental errors, it will be hard to find a computational method that outperforms $\operatorname{CCSD}(\mathrm{T})$ at a realistic computational cost; the precision and accuracy are, roughly, within $5 \%$ of the typical total $\mathrm{BDE}$ and justifies using $\operatorname{CCSD}(\mathrm{T})$ to analyze the drivers of M-O bonding for the entire $3 \mathrm{~d}, 4 \mathrm{~d}$, and $5 \mathrm{~d}$ transition series in systemic comparison.

We also note from Table 2 that CCSD performs much worse than CCSD(T). The importance of including (by perturbation approximation) the triplet excitations is massive, leading to a halving of the MAE and essential removal of the large systematic under-binding tendency of 
CCSD. In accordance with this, it was found previously that the description of splitting parameters for some of the $3 \mathrm{~d}$ metals improves by $\approx 0.2 \mathrm{eV}$ when going from $\operatorname{CCSD}$ to $\operatorname{CCSD}(\mathrm{T}) .{ }^{58}$

Table 2. Mean absolute error (MAE), mean signed error (MSE), standard deviation (STD) of the SE, STD of the AE, and the largest positive SE and negative SE for CCSD and CCSD(T).

\begin{tabular}{|l|l|l|l|l|l|l|}
\hline Method & MAE & MSE & STD of SE & STD of AE & $\begin{array}{l}\text { Largest } \\
\text { positive error }\end{array}$ & $\begin{array}{l}\text { Largest } \\
\text { negative } \\
\text { error }\end{array}$ \\
\hline CCSD & 50.2 & -49.0 & 31.2 & 29.2 & $33.8\left(\mathrm{AuO}^{+}\right)$ & $-123.9(\mathrm{OsO})$ \\
\hline CCSD(T) & 24.8 & 3.0 & 31.5 & 19.4 & $63.7\left(\mathrm{AuO}^{+}\right)$ & $-75.5\left(\mathrm{AgO}^{+}\right)$ \\
\hline
\end{tabular}

A radar plot such as Figure 1A-1B as previously used ${ }^{59}$ is a convenient way to visualize systems with errors larger than average (tabulated errors are in Table S15). An error of $30 \mathrm{~kJ} / \mathrm{mol}$ is highlighted by the red line in Figure 1A-1B. Systems with errors exceeding this threshold are TiO, $\mathrm{NbO}, \mathrm{TcO}, \mathrm{RuO}, \mathrm{LaO}, \mathrm{TaO}, \mathrm{WO}, \mathrm{OsO}, \mathrm{IrO}, \mathrm{PtO}, \mathrm{TiO}^{+}, \mathrm{MnO}^{+}, \mathrm{NiO}^{+}, \mathrm{NbO}^{+}, \mathrm{PdO}^{+}, \mathrm{AgO}^{+}$, $\mathrm{LaO}^{+}, \mathrm{TaO}^{+}, \mathrm{OsO}^{+}$and $\mathrm{AuO}^{+}$. The average reported experimental uncertainty for these 20 systems is $23 \mathrm{~kJ} / \mathrm{mol}$ and includes five cases with no listed experimental uncertainty. Thus the average experimental uncertainty for this group is larger than for the whole dataset $(17 \mathrm{~kJ} / \mathrm{mol})$. The difficult cases include four $3 \mathrm{~d}$ systems, six $4 \mathrm{~d}$ systems and $105 \mathrm{~d}$ systems. Thus, the $5 \mathrm{~d}$ metals are slightly more challenging to describe, possibly due to the relativistic effects not being perfectly described by the applied methodology; we estimate a possible error of $\sim 5-10 \mathrm{~kJ} / \mathrm{mol}$ for the $5 \mathrm{~d}$ systems where the SOC correction typically has its largest magnitude. This error would largely explain the slightly larger errors of the $5 \mathrm{~d}$ systems.

To test the trend chemistry of our protocol, Figure 1C shows the linear relationship between the experimental BDEs from Table 1 and the BDEs computed using $\operatorname{CCSD}(\mathrm{T})$. The trend prediction of $\operatorname{CCSD}(\mathrm{T})$ is excellent, with a $\mathrm{R}^{2}$ value of 0.98 . The trend chemistry is the most 
important feature of computational chemistry as it enables the relative comparison of chemical systems as required e.g. for judging the relative performance of two metal catalysts. Thus $\operatorname{CCSD}(\mathrm{T})$ is perfectly suited for understanding complete trend chemistry of the d-transition metals. The slope of 0.97 and intercept of 12.18 also shows that $\operatorname{CCSD}(\mathrm{T})$ interpolates well across all binding strength regimes and down to the zero bonding regime, and that the computed bond strengths are well-balanced across the whole range of BDEs studied.

Figure 1D shows the linear correlation between experimental ionization potentials (IP) and CCSD(T)-computed IPs (tabulated values are in Table S16). The correlation is very strong with $\mathrm{R}^{2}=0.99$ and shows that any computational difficulty in describing the M-O BDEs is not caused by the atomic $\mathrm{M}$ or $\mathrm{M}^{+}$states but rather the $\mathrm{M}-\mathrm{O}$ or $\mathrm{M}-\mathrm{O}^{+}$states. This conclusion is also supported by Figure $\mathbf{S 2}$ showing no correlation between the errors of the IPs and the errors of the BDEs.

\section{Trend chemistry of M-O bonds: Net d-Bonding}

The trend agreement of Figure 1C relates to the overall data set, without any consideration of the important variations specific to the $3 \mathrm{~d}, 4 \mathrm{~d}$, and $5 \mathrm{~d}$ transition series. In order test the performance of $\operatorname{CCSD}(\mathrm{T})$ for these periodic trends, Figure 2 shows the variation of the BDE for the transition metal oxides divided by transition period for both the neutral and cationic systems, using the experimental values of Table 1 and the $\operatorname{CSD}(\mathrm{T})$-computed values of Table S12. Computations and experiment agree on the same general trends; regardless of being $3 \mathrm{~d}$, $4 \mathrm{~d}$ or $5 \mathrm{~d}$ metals the strongest metal oxygen bonds are seen for the early transition metals as expected, with a tendency to decrease towards the right, but with a hump at group 4-5 and a less pronounced hump at group 8-9, and a local minimum relative to the diagonal background trend at group 7 for the $3 d$ and $4 d$ metals and at group 8 for the $5 \mathrm{~d}$ metals. This behavior is characteristic for all three periods and for both $\mathrm{MO}$ and $\mathrm{MO}^{+}$systems and has as its most important feature a rapid drop in BDE towards the middle of the series. The general two-hump structure is also well-reproduced by DFT (PBE). ${ }^{40}$ 
The structure resembles that of the hydration free energies of the transition metals which is caused by a combination of an underlying left-right linear trend of effective nuclear charge and an hump structure caused by orbital effects, specifically occupation of the antibonding d-orbitals ( $\mathrm{e}_{\mathrm{g}}$ orbitals in $\mathrm{O}_{\mathrm{h}}$ symmetry) in high-spin hexaqua metal complexes. ${ }^{60}$ Since the M-O BDE pattern emerges already in the experimental data it has been noted before.$^{61}$ In the case of the M-O BDEs, the humps are also orbital effects on a linear background trend to be analyzed further below.

The explanations for the relative M-O BDEs differ substantially in the literature ${ }^{12,61,62}$, yet these relative BDEs are the basis of the oxophilicity of the metals and thus their general activity towards oxygen. ${ }^{15}$ It has been suggested that oxygen lone pairs can donate electron density to empty $d$ orbitals on the transition metal ${ }^{34}$ to strengthen the bonds, which would make bonding stronger for early metals since they have relatively more empty d orbitals. However, we can see that the pattern in Figure 2 can be constructed from a linear non-orbital background effect that is, importantly, reverse that of the hydration free energies but arising from a similar monotonous leftright trend in the periodic table, combined with an d-orbital effect that is not determined by having empty d-orbitals available for oxygen lone pairs. On the contrary, this is a net orbital bonding effect resembling that of the ligand field stabilization effect of complexes.

To understand the orbital hump effect first, the MO species are characterized by gradual high-spin aufbau of the five valence orbitals, the $\sigma$-orbital, the two-fold degenerate $\delta_{\mathrm{d}}$ orbital level, and the two-fold degenerate $\pi_{\mathrm{d}}$ orbital level. ${ }^{12}$ Thus, the spin state increases monotonically from ${ }^{2} \Sigma^{+}$for $\mathrm{ScO}$ with $\sigma^{1}$ occupation, to $\mathrm{MnO}$ with a ${ }^{6} \Sigma^{+}$state i.e. one electron in each of the five orbitals. The $\delta$-level is bonding as inferred from the equilibrium bond lengths, ${ }^{12}$ whereas a consistent explanation for the data is that the $\pi$-level is antibonding with respect to the M-O bond. This is not surprising considering that these two orbitals are higher in energy than the $\delta$-orbitals, probably because the $\pi$-orbitals point directly towards the two oxygen lone pairs in a double bond model of M-O bonding. This simple explanation explains the two humps in Figure 2 well, as group 4 (TiO) 
reaches maximal bond order, which then decreases with occupation of $\pi$-orbitals, and increases again with the occupation of the second electron in each of the bonding $\delta$-orbitals, and finally decreases again towards very small bond order in the group 11 and 12 metal oxides.

The involvement of d-orbital energies in metal-ligand bonding is a common rationale for reduced chemisorption on metal surfaces. On surfaces, the net-d-bonding effect is reduced because the symmetry is changed and the spin states coupled, such that trends in chemisorption energies have less pronounced humps. This effect explains a substantial part of the difference between the molecular and surface states, as shown previously ${ }^{40}$. In the molecular bonding regime of Figure 2, the antibonding d-orbital occupation explains the humps, whereas the dominating trend in $\mathrm{M}-\mathrm{O}$ BDEs is the periodic linear trend caused by the effective nuclear charge, which correlates with the filling of the d-orbitals (hence the success of models that simply assume reactivity based on dorbital filling). Both the net-d-bonding (producing the humps) and the total d-occupation (producing the linear background trend) are important as is also the case for hydration free energies of the transition metal ions. Because the $\operatorname{CCSD}(\mathrm{T})$ captures these trends excellently (Figure 2), we can use the computed electronic structures to rationalize the main drivers of M-O bonding.

\section{Charge and Spin as Descriptors of M-O Bonding}

After having established the accuracy of $\operatorname{CCSD}(\mathrm{T})$ for the $\mathrm{M}-\mathrm{O}$ bonds, we now turn to the second aim of the study, to identify suitable descriptors of the strength of the metal-oxygen interaction. Figure 3A-3F shows the atomic charges on oxygen and the metal and the spin densities on oxygen and the metal for the 60 transition metal oxides from a DFT-based natural population analysis ${ }^{63-}$ ${ }^{65}$ (B3LYP/aug-cc-pV5Z/def2-QZVPPD) using the same states as for the ground state CCSD(T) computations. A notable linear trend is seen in the less negative oxygen charge and corresponding loss of positive metal charge towards the right of the periodic table, with the group 12 metals partly 
breaking the trend. Accordingly, the polarity of the M-O bonds decreases towards the right, with the dipole moments explicitly shown in Figure S3. The trend is more pronounced for the $4 \mathrm{~d}$ and $5 \mathrm{~d}$ metals and for the cationic molecules and largely follows the electronegativity difference between the metal and oxygen (Figure $\mathbf{S 4}, \mathrm{R}^{2}=0.68$ ).

Figure 3 also shows humps in the spin densities on the metal in the middle of the d-blocks, caused by the high-spin aufbau. Interestingly, despite this the spin density on oxygen stays nearly constant up to group 6 and then grows monotonically until group 11 (the coinage metals), and then the trend is again broken in group 12 cations and the $3 \mathrm{~d}$ neutral diatomics. For the early d-transition metals the spin density on oxygen is nearly zero, i.e. the electrons of oxygen are paired because they are involved in forming bonding orbitals to the metal centers. The trend of spin density on oxygen correlates with the BDE (Figure S5), such that a larger spin density on oxygen gives a lower BDE, and approaches almost 2, that of free oxygen, in the weakly binding coinage metals (tabulated values available in Tables S17-S22). These findings are not sensitive to method choice, as functionals B3LYP, $\mathrm{PBE}^{66}$ and BLYP ${ }^{67,68}$ and both NPA and Mulliken analysis produce similar trends. The six different methods produce $\mathrm{R}^{2}$ values of $0.64-0.70$.

\section{Electronegativity drives M-O bond strengths}

Whereas the orbital effect causing the hump structure was analyzed and explained above, we still need to discuss the dominating linear periodic trend in Figure 2. The figure reflects the general knowledge that early transition metals bind more strongly to oxygen. This is also the case however for e.g. sulfur such that the M-O or M-S bond strength alone is not enough to separate oxophilic and thiophilic elements; the relative strength is required ${ }^{15}$. It is notable that the trend in Figure 2 is reverse of that expected from metal ion hydration, where more favorable hydration (stronger M-O bonding) occurs to the right due to stronger effective nuclear charge as the diffuse d-orbitals 
become occupied, with a modulating influence of the ligand field stabilization due to d-orbital occupation. ${ }^{60}$ This is curiously opposite to the periodic linear trend in M-O BDEs. However, the difference emerges directly from the picture of M-O bonding advanced by the oxophilicity scale ${ }^{15}$ which is dominated not by the hardness, orbital effects, or effective nuclear charge of the metal but by the electronegativity difference between $\mathrm{M}$ and $\mathrm{O}$, which determines the bond strength of a strong polar covalent bond viz. the original definition of electronegativity by Pauling. ${ }^{69,70}$

To show that this is indeed the case, Figure 4A and 4B presents the linear relationship between the experimental Mulliken electronegativity of the transition metal and the experimental and $\operatorname{CCSD}(\mathrm{T})$-computed BDEs. $\mathrm{R}^{2}$ is 0.47 and 0.49 , respectively, showing that electronegativity drives a substantial part of the total trend in $\mathrm{M}-\mathrm{O}$ bond strength. For the individual $3 \mathrm{~d}, 4 \mathrm{~d}$, and $5 \mathrm{~d}$ series, correlation is stronger with $\mathrm{R}^{2}$ ranging from 0.75 to 0.90 , because the covalency of the M$\mathrm{O}$ bond increases more down through the periods than within each period. The $\mathrm{R}^{2}$-values show that a dominating contribution to the relative M-O BDE in Figure 2 is the electronegativity, giving the linear trend. The remaining feature is the antibonding d-orbital effect; both effects are clearly required to rationalize the $\mathrm{M}-\mathrm{O}$ bond strengths.

In the model that we emphasize here, electronegativity plays the central role for the trend in ligand and adsorbate binding to the d-transition metals. Models emphasizing the filling of dorbitals and d-bands, such as the powerful d-band center model by Varma and Wilson ${ }^{71}$, can also account for ionic and covalent contributions to metal-ligand binding. The reason both models work is that these bonds are polar covalent, and the ionic stabilization decreases with effective nuclear charge of the metals because it reduces the difference in electronegativity such that the ionic stabilization contribution disappears towards the right of the d-transition series, producing the weakest M-L bonds. The energy of the d-band, as other orbital levels, decreases with effective nuclear charge and thus correlates with this trend, making it a decent descriptor. The electronegativity model predicts that the metal with the lowest electronegativity should have the 
largest interaction with oxygen, and vice versa. As seen from Figure 4A the experimental trend is in excellent agreement with this hypothesis showing that a lower electronegativity on the metal leads to a stronger BDE. The physical reason is that oxygen, being the second-most electronegative element of the periodic table, enforces an oxide-like character in the covalent bonding, making the ionic component extremely important for the trend chemistry, as the ability to satisfy oxygen's electron demand grows rapidly towards the left of the periodic table where electronegativity is low, and the effect amounts to many hundreds of $\mathrm{kJ} / \mathrm{mol}$, and thus dominates the trends in binding.

The strength of the metal-oxygen bond is of major catalytic interest since a stronger M-O bond is associated with a more favorable chemisorption and $\mathrm{O}-\mathrm{O}$ bond activation ${ }^{3}$. A very important question raised by van Santen and Tranca ${ }^{40}$ is how much of the experimentally observed trend chemistry of different catalysts is due to the $\mathrm{M}-\mathrm{O}$ bonds and how much is due to modulating effects of the remaining catalyst (e.g. metal-metal bonding). One could imagine that the trend accuracy for the $\mathrm{M}-\mathrm{O}$ bonding is more important than including other modulating effects of the catalyst at the cost of worse M-O trend accuracy. If this is the case, it is more important to study relative $\mathrm{M}-\mathrm{O}$ bond strengths of small systems with an accurate method such as $\operatorname{CCSD}(\mathrm{T})$ or a very good density functional than including the smaller modulating effects of the other atoms of the catalysts. Suitably performing functionals have been established for the $3 \mathrm{~d}$ metal oxides ${ }^{19}$, although the universality for all data in Table 1 remains unclear. The very large values and very large spread in M-O BDEs from 100-800 kJ/mol support this hypothesis.

Figure 4C and Figure 4D show the linear correlation between the oxophilicity ${ }^{15}$ and the experimental and computed BDEs, respectively. Figure 4C shows that the oxophilicity of the transition metals correlates strongly with the experimental diatomic BDE, which is not surprising as they feature as part of the definition of the scale. However, the oxophilicity correlates strongly with a chemical reactivity across the d-transition metals and rationalize both ore mineralization and catalytic activity in a wide range of reactions. ${ }^{15}$ Similarly, the periodic and orbital trends of 
the first coordination sphere defines the chemical reactivity and free energies of hydration of the transition metal ions in water ${ }^{60,72}$, which reflect condense systems. Finally, Figure 4D shows that $\operatorname{CCSD}(\mathrm{T})$ BDEs also correlate highly significantly with the oxophilicity $\left(\mathrm{p}=2.6 \cdot 10^{-10}\right)$.

To further confirm our hypothesis that the local M-O bond has a major influence on the chemistry of real systems, we plotted the chemisorption energies computed recently by DFT for pure metal surfaces where metal-metal modulation and long-range effects are included ${ }^{73}$ as seen in Figure 5. Despite reflecting surfaces with high-coverage, which might weaken correlation, Figure 5A shows excellent correlation $\left(\mathrm{R}^{2}=0.84\right)$ between random-phase approximation (RPA) computed chemisorption energies, which accurately reproduce experimental adsorption energies ${ }^{73}$ and the experimental M-O BDEs of Table 1. This supports our hypothesis that the local M-O BDE is the major driver of energetic trends of real systems, and that oxophilicity (the best descriptor of M-O BDEs) can accordingly be used as a descriptor for larger transition metals systems reacting with oxygen. The inverse relationship arises from the stronger $\mathrm{M}-\mathrm{O}$ bonding leading to more exothermic chemisorption due to back-bonding to $\pi^{*}$ that weakens the O-O bond.

Figure 5B shows the correlation between PBE-computed adsorption energies ${ }^{73}$ and the experimental M-O BDEs ( $\mathrm{R}^{2}$ of 0.82 ), and Figure 5C shows the correlation between PBEcomputed chemisorption energies ${ }^{73}$ and PBE-computed M-O BDEs (using the same basis set as for $\operatorname{CCSD}(\mathrm{T}), \mathrm{ZPE}$ and relativistic corrections). The correlation is very strong with $\mathrm{R}^{2}=0.89$ indicating that metal-metal modulating influences explain very little of the variation in the chemisorption energies, the majority being described by the local M-O BDE, consistent with its large variation of hundreds of $\mathrm{kJ} / \mathrm{mol}$ (average $\mathrm{BDE}=472 \mathrm{~kJ} / \mathrm{mol}$ and standard deviation $=221$ $\mathrm{kJ} / \mathrm{mol}$ ). Finally Figure 5D shows the correlation between RPA-computed adsorption energies and the CCSD(T)-computed M-O BDEs $\left(\mathrm{R}^{2}=0.84\right)$. The regressions of Figures 5A-5D are highly significant with p-values in all cases smaller than $10^{-8}$ and have standard residual errors of 56, 63, 48 , and $54 \mathrm{~kJ} / \mathrm{mol}$, respectively, or about $10 \%$ of the typical M-O BDE. The $48 \mathrm{~kJ} / \mathrm{mol}$ for PBE 
reflects the expected error of predicting the surface adsorption energy from the pure M-O BDE without accounting for surface effects. Because the local point group symmetry of the metal surface on-top $\mathrm{M}-\mathrm{O}$ bond is $\mathrm{C}_{4 \mathrm{v}}$ rather than $\mathrm{C}_{\infty \mathrm{v}}$ as for the diatomics, the orbital effect causes the main hump at group 5 in the surface trend instead of 4 as in the M-O trend, but the overall characteristics, energy and error drivers are otherwise the same.

When comparing the diatomic metal oxides with transition metal surfaces one should note the potential changes in spin states, which may affect the difference between the molecular and surface systems ${ }^{40}$. As seen from Table S4 and Table S6, many of the metals and metal oxides have high spin multiplicities, whereas surfaces may be both spin-paired (diamagnetic) and locally unpaired (paramagnetic), and spin pairing will thus affect the comparison to the metal states ${ }^{74}$. To examine whether spin state effects weaken the correlations in Figure 5, we calculated the BDEs of all systems using either the metals in their lowest possible spin state, the diatomic molecule in its lowest possible spin state, or both metal and molecule in their lowest possible spin state. The results in Figure S6 and Tables S23-S25 show that enforcing a low-spin state on the metal produces a higher $\mathrm{BDE}$ and making $\mathrm{MO}$ low spin gives a lower BDE, as the two states are destabilized relative to their high-spin ground states. The case of low spin for both M and MO thus lies between these two extremes (gray lines in Figure S6), and closest to the experimental M-O BDEs (blue in Figure S6). The cancellation of energy shifts due to d-orbital occupations in the metal and metal-ligand states may partly explain the ability of the M-O BDE to describe surface energetics despite potentially different d-orbital occupations, as discussed before ${ }^{40}$. However, the bump structure caused by enforcing low-spin in any of the states (Figure S6) is very exaggerated relative to surface energetics ${ }^{73}$, showing that local high-spin aufbau of d-orbitals is a good basis for molecular descriptors of most surface states (i.e. local weak-field environment of metal atoms in the surface), which is also the reason paramagnetic metals exist in the first place. The main 
reason for the descriptor qualities of the molecular BDE is however still the dominance of the linear trend due to effective nuclear charge, which is similar for the two types of systems.

In conclusion, diatomic M-O BDEs computed using $\mathrm{CCSD}(\mathrm{T})$ are an excellent descriptor of the reactivity of full-size transition metal systems reacting with oxygen. Because of this, the conclusions on trend chemistry explained above and the drivers of M-O bonding are transferable to real systems and thus our analysis explains the large differences in chemisorption of oxygen on metal surfaces as due to primarily the effect of electronegativity, which drives oxophilicity, and secondarily to d-orbital net bonding. Both effects are important in describing the precise relative reactivity towards oxygen as required for e.g. catalyst design.

\section{Conclusions}

The chemical bonds between a d-transition metal and oxygen are immensely important in catalysis, biology, astrophysics and mineralogy. To identify an adequate benchmark for the entire $3 \mathrm{~d}, 4 \mathrm{~d}$, and $5 \mathrm{~d}$ transition series and understand the trends in the bonding of the transition metal oxides, a complete data set of the diatomic transition metal oxides was studied using CCSD(T) with adequate basis sets and corrections for vibrational and relativistic effects.

The main findings of this work are: (1) By curating and comparing experimental data against $\operatorname{CCSD}(\mathrm{T})$ and the experimental trend chemistry, we define a recommended benchmark data set for the diatomic transition metal oxide BDEs (Table 1). (2) We show that CCSD(T) has excellent trend prediction compared with experiment and is able to produce BDEs at almost the same level of accuracy as experiment. We can therefore recommend its use to guide the choice and development of density functionals for d-transition metal-oxygen chemistry when experimental data are not accessible. This tendency will be accelerated by developments that enable the study of larger molecular systems by coupled-cluster theories. ${ }^{32}$ (3) The BDEs of the 
diatomic transition metal oxides decrease linearly towards the right in all three transition metal series, modulated by a hump structure at groups 4-5 and a less pronounced hump at groups 8-9 (Figure 2). (4) The trend in BDE is explained by two effects: The linear trend is caused by the increasing electronegativity towards right in the transition metal series, which reduces the strength of the polar covalent bonding with oxygen. The hump structure is in contrast caused by occupation of bonding $\delta$-orbitals or antibonding $\pi$-orbitals; the electronegativity effect dominates over the $\mathrm{d}$ orbital effect. (5) The diatomic MO BDE correlates strongly with oxophilicity and energies of chemisorption on pure metal surfaces, showing that the local M-O bond directs the energetics and chemistry of real transition metal systems, and thus the M-O BDE may be used as a descriptor for the reactivity. (6) It follows that theoretical models should describe the local M-O bonding with particularly high accuracy when oxygen is the major species of interest in larger systems e.g. for the catalytic cycle of water splitting. The importance of the local M-O bond justifies the study of the diatomic systems and substantially qualifies their importance for understanding larger systems in a "bottom-up" approach to theoretical catalysis.

\section{Acknowledgments}

We acknowledge the use of the High-Performance Computing Cluster at DTU.

\section{Supporting Information available}

The Supporting information file contains the experimental data set for the $29 \mathrm{M}-\mathrm{O}$ systems and 28 $\mathrm{M}^{+}-\mathrm{O}$ systems, bond lengths used, computed electronic energies, BDEs, linear correlation plots and various other figures and tables referenced in the text. This information is available free of charge at https://pubs.acs.org/ 


\section{References}

(1) Liu, L.; Corma, A. Metal Catalysts for Heterogeneous Catalysis: From Single Atoms to Nanoclusters and Nanoparticles. Chem. Rev. 2018, 118, 4981-5079.

(2) Periana, R. A.; Taube, D. J.; Gamble, S.; Taube, H.; Satoh, T.; Fujii, H. Platinum Catalysts for the High-Yield Oxidation of Methane to a Methanol Derivative. Science 1998, 280, 560564.

(3) Kulkarni, A.; Siahrostami, S.; Patel, A.; Nørskov, J. K. Understanding Catalytic Activity Trends in the Oxygen Reduction Reaction. Chem. Rev. 2018, 118, 2302-2312.

(4) Liang, Q.; Wu, X.; Weng, D.; Xu, H. Oxygen Activation on Cu/Mn-Ce Mixed Oxides and the Role in Diesel Soot Oxidation. Catal. Today 2008, 139, 113-118.

(5) Gong, Y.; Zhou, M.; Andrews, L. Spectroscopic and Theoretical Studies of Transition Metal Oxides and Dioxygen Complexes. Chem. Rev. 2009, 109, 6765-6808.

(6) Sawa, A. Resistive Switching in Transition Metal Oxides. Mater. today 2008, 11, 28-36.

(7) Post, J. E. Manganese Oxide Minerals: Crystal Structures and Economic and Environmental Significance. Proc. Natl. Acad. Sci. 1999, 96, 3447-3454.

(8) Buddington, A. F.; Lindsley, D. H. Iron-Titanium Oxide Minerals and Synthetic Equivalents. J. Petrol. 1964, 5, 310-357.

(9) Collman, J. P.; Boulatov, R.; Sunderland, C. J.; Fu, L. Functional Analogues of Cytochrome c Oxidase, Myoglobin, and Hemoglobin. Chem. Rev. 2004, 104, 561-588.

(10) Solomon, E. I.; Heppner, D. E.; Johnston, E. M.; Ginsbach, J. W.; Cirera, J.; Qayyum, M.; Kieber-Emmons, M. T.; Kjaergaard, C. H.; Hadt, R. G.; Tian, L. Copper Active Sites in 
Biology. Chem. Rev. 2014, 114, 3659-3853.

(11) De Montellano, P. R. O. Cytochrome P450: Structure, Mechanism, and Biochemistry; Kluwer Academic/Plenum Publishers, New York, 2005.

(12) Merer, A. J. Spectroscopy of the Diatomic 3d Transition Metal Oxides. Annu. Rev. Phys. Chem. 1989, 40, 407-438.

(13) Yang, X.-F.; Wang, A.; Qiao, B.; Li, J.; Liu, J.; Zhang, T. Single-Atom Catalysts: A New Frontier in Heterogeneous Catalysis. Acc. Chem. Res. 2013, 46, 1740-1748.

(14) Sun, S.; Zhang, G.; Gauquelin, N.; Chen, N.; Zhou, J.; Yang, S.; Chen, W.; Meng, X.; Geng, D.; Banis, M. N. Single-Atom Catalysis Using Pt/Graphene Achieved through Atomic Layer Deposition. Sci. Rep. 2013, 3, 1775.

(15) Kepp, K. P. A Quantitative Scale of Oxophilicity and Thiophilicity. Inorg. Chem. 2016, 55, 9461-9470.

(16) Lejaeghere, K.; Bihlmayer, G.; Björkman, T.; Blaha, P.; Blügel, S.; Blum, V.; Caliste, D.; Castelli, I. E.; Clark, S. J.; Dal Corso, A. Reproducibility in Density Functional Theory Calculations of Solids. Science 2016, 351, aad3000.

(17) Hammer, B.; Nørskov, J. K. Theoretical Surface Science and Catalysis-calculations and Concepts. In Impact of Surface Science on Catalysis; Academic Press, 2000; Vol. 45, pp $71-129$.

(18) Luo, Y.-R. Comprehensive Handbook of Chemical Bond Energies, 1st ed., CRC Press, 2007.

(19) Moltved, K. A.; Kepp, K. P. Chemical Bond Energies of 3d Transition Metals Studied by Density Functional Theory. J. Chem. Theory Comput. 2018, 14, 3479-3492. 
(20) Moltved, K. A.; Kepp, K. P. The Metal Hydride Problem of Computational Chemistry: Origins and Consequences. J. Phys. Chem. A 2019, 123, 2888-2900.

(21) Aoto, Y. A.; de Lima Batista, A. P.; Köhn, A.; de Oliveira-Filho, A. G. S. How to Arrive at Accurate Benchmark Values for Transition Metal Compounds: Computation or Experiment? J. Chem. Theory Comput. 2017, 13, 5291-5316.

(22) Xu, X.; Zhang, W.; Tang, M.; Truhlar, D. G. Do Practical Standard Coupled Cluster Calculations Agree Better than Kohn-Sham Calculations with Currently Available Functionals When Compared to the Best Available Experimental Data for Dissociation Energies of Bonds to 3d Transition Metals? J. Chem. Theory Comput. 2015, 11, 2036-2052.

(23) Shee, J.; Rudshteyn, B.; Arthur, E. J.; Zhang, S.; Reichman, D. R.; Friesner, R. A. On Achieving High Accuracy in Quantum Chemical Calculations of $3 d$ Transition MetalContaining Systems: A Comparison of Auxiliary-Field Quantum Monte Carlo with Coupled Cluster, Density Functional Theory, and Experiment for Diatomic Molecules. $J$. Chem. Theory Comput. 2019, 15, 2346-2358.

(24) Fang, Z.; Vasiliu, M.; Peterson, K. A.; Dixon, D. A. Prediction of Bond Dissociation Energies/Heats of Formation for Diatomic Transition Metal Compounds: CCSD(T) Works. J. Chem. Theory Comput. 2017, 13, 1057-1066.

(25) Cheng, L.; Gauss, J.; Ruscic, B.; Armentrout, P. B.; Stanton, J. F. Bond Dissociation Energies for Diatomic Molecules Containing 3d Transition Metals: Benchmark ScalarRelativistic Coupled-Cluster Calculations for 20 Molecules. J. Chem. Theory Comput. 2017, 13, 1044-1056.

(26) Morse, M. D. Predissociation Measurements of Bond Dissociation Energies. Acc. Chem. Res. 2019, 52, 119-126. 
(27) Jiang, W.; DeYonker, N. J.; Wilson, A. K. Multireference Character for 3d TransitionMetal-Containing Molecules. J. Chem. Theory Comput. 2012, 8, 460-468.

(28) Finley, J.; Malmqvist, P.-Å.; Roos, B. O.; Serrano-Andrés, L. The Multi-State CASPT2 Method. Chem. Phys. Lett. 1998, 288, 299-306.

(29) Phung, Q. M.; Feldt, M.; Harvey, J. N.; Pierloot, K. Toward Highly Accurate Spin State Energetics in First-Row Transition Metal Complexes: A Combined CASPT2/CC Approach. J. Chem. Theory Comput. 2018, 14, 2446-2455.

(30) Radoń, M. Benchmarking Quantum Chemistry Methods for Spin-State Energetics of Iron Complexes against Quantitative Experimental Data. Phys. Chem. Chem. Phys. 2019, 21, $4854-4870$.

(31) Zobel, J. P.; Nogueira, J. J.; González, L. The IPEA Dilemma in CASPT2. Chem. Sci. 2017, $8,1482-1499$.

(32) Liakos, D. G.; Sparta, M.; Kesharwani, M. K.; Martin, J. M. L.; Neese, F. Exploring the Accuracy Limits of Local Pair Natural Orbital Coupled-Cluster Theory. J. Chem. Theory Comput. 2015, 11, 1525-1539.

(33) Nakao, Y.; Hirao, K.; Taketsugu, T. Theoretical Study of First-Row Transition Metal Oxide Cations. J. Chem. Phys. 2001, 114, 7935-7940.

(34) Bauschlicher, C. W.; Maitre, P. Theoretical Study of the First Transition Row Oxides and Sulfides. Theor. Chim. Acta 1995, 90, 189-203.

(35) Siegbahn, P. E. M. A Comparison of the Bonding in the Second-Row Transition-Metal Oxides and Carbenes. Chem. Phys. Lett. 1993, 201, 15-23.

(36) Nakajima, Y.; Seino, J.; Nakai, H. Relativistic Effect on Enthalpy of Formation for 
Transition-Metal Complexes. Chem. Phys. Lett. 2017, 673, 24-29.

(37) Zhao, Y.; Truhlar, D. G. Comparative Assessment of Density Functional Methods for 3 d Transition-Metal Chemistry. J. Chem. Phys. 2006, 124, 224105.

(38) Rinaldo, D.; Tian, L.; Harvey, J. N.; Friesner, R. A. Density Functional Localized Orbital Corrections for Transition Metals. J. Chem. Phys. 2008, 129, 164108.

(39) Siegbahn, P. E. M.; Blomberg, M. R. A. Transition-Metal Systems in Biochemistry Studied by High-Accuracy Quantum Chemical Methods. Chem. Rev. 2000, 100, 421-438.

(40) Van Santen, R. A.; Tranca, I. How Molecular Is the Chemisorptive Bond? Phys. Chem. Chem. Phys. 2016, 18, 20868-20894.

(41) Turbomole software, version 7.0. University of Karlsruhe and Forschungszentrum Karlsruhe GmbH, 2012, available from http://www.turbomole.com.

(42) Sierka, M.; Hogekamp, A.; Ahlrichs, R. Fast Evaluation of the Coulomb Potential for Electron Densities Using Multipole Accelerated Resolution of Identity Approximation. $J$. Chem. Phys. 2003, 118, 9136-9148.

(43) Perdew, J. Density-Functional Approximation for the Correlation Energy of the Inhomogenous Electron Gas. Phys. Rev. B 1986, 33, 8822-8824.

(44) Becke, A. D. Density-Functional Exchange-Energy Approximation with Correct Asymptotic-Behavior. Phys. Rev. A 1988, 38, 3098-3100.

(45) Weigend, F.; Ahlrichs, R. Balanced Basis Sets of Split Valence, Triple Zeta Valence and Quadruple Zeta Valence Quality for H to Rn: Design and Assessment of Accuracy. Phys. Chem. Chem. Phys. 2005, 7, 3297-3305.

(46) Jensen, K. P.; Roos, B. O.; Ryde, U. Performance of Density Functionals for First Row 28 
Transition Metal Systems. J. Chem. Phys. 2007, 126, 014103.

(47) Dunning, T. H. Gaussian Basis Sets for Use in Correlated Molecular Calculations. I. The Atoms Boron through Neon and Hydrogen. J. Chem. Phys. 1989, 90, 1007-1023.

(48) Kepp, K. P. Trends in Strong Chemical Bonding in $\mathrm{C}_{2}, \mathrm{CN}, \mathrm{CN}^{-}, \mathrm{CO}, \mathrm{N}_{2}, \mathrm{NO}, \mathrm{NO}^{+}$, and O 2. J. Phys. Chem. A 2017, 121, 9092-9098.

(49) Kramida, A.; Ralchenko, Y.; Reader, J.; NIST ASD Team (2018). NIST Atomic Spectra Database (ver. 5.5.6).

(50) Wolf, A.; Reiher, M.; Hess, B. A. The Generalized Douglas-Kroll Transformation. J. Chem. Phys. 2002, 117, 9215-9226.

(51) Reiher, M. Douglas-Kroll-Hess Theory: A Relativistic Electrons-Only Theory for Chemistry. Theor. Chem. Acc. 2006, 116, 241-252.

(52) Weigend, F.; Baldes, A. Segmented Contracted Basis Sets for One- and Two-Component Dirac-Fock Effective Core Potentials. J. Chem. Phys. 2010, 133, 174102.

(53) von Szentpály, L. Atom-Based Thermochemistry: Predictions of the Sublimation Enthalpies of Group 12 Chalcogenides and the Formation Enthalpies of Their Polonides. $J$. Phys. Chem. A 2008, 112, 12695-12701.

(54) Rumble, J. R. CRC Handbook of Chemistry and Physics, 99th Edition; CRC Handbook of Chemistry and Physics; CRC Press LLC, 2018.

(55) Luo, Y.-R. Handbook of Bond Dissociation Energies in Organic Compounds, 1st ed.; CRC Press, 2002.

(56) Johnson, E. R.; Becke, A. D. Communication: DFT Treatment of Strong Correlation in 3d Transition-Metal Diatomics. J. Chem. Phys. 2017, 146, 211105. 
(57) Kepp, K. P. Accuracy of Theoretical Catalysis from a Model of Iron-Catalyzed Ammonia Synthesis. Commun. Chem. 2018, 1, 63.

(58) Rishi, V.; Perera, A.; Bartlett, R. Transition Metal Atomic Multiplet States through the Lens of Single-Reference Coupled-Cluster and the Equation-of-Motion Coupled-Cluster Methods. Theor. Chem. Acc. 2014, 133, 1515.

(59) Siig, O. S.; Kepp, K. P. Iron (II) and Iron (III) Spin Crossover: Toward an Optimal Density Functional. J. Phys. Chem. A 2018, 122, 4208-4217.

(60) Kepp, K. P. Thermochemically Consistent Free Energies of Hydration for Di-and Trivalent Metal Ions. J. Phys. Chem. A 2018, 122, 7464-7471.

(61) Bakalbassis, E. G.; Stiakaki, M.-A. D.; Tsipis, A. C.; Tsipis, C. A. Ground and Low-Lying Excited State Properties of the First-Row Transition-Metal Oxide Diatomics Calculated by an Improved ASED-MO Model. Chem. Phys. 1996, 205, 389-399.

(62) Fiedler, A.; Schroeder, D.; Shaik, S.; Schwarz, H. Electronic Structures and Gas-Phase Reactivities of Cationic Late-Transition-Metal Oxides. J. Am. Chem. Soc. 1994, 116, $10734-10741$.

(63) Stephens, P. J.; Devlin, F. J.; Chabalowski, C. F.; Frisch, M. J. Ab Initio Calculation of Vibrational Absorption and Circular Dichroism Spectra Using Density Functional Force Fields. J. Phys. Chem. 1994, 98, 11623-11627.

(64) Lee, C.; Yang, W.; Parr, R. G. Development of the Colle-Salvetti Correlation-Energy Formula into a Functional of the Electron Density. Phys. Rev. B 1988, 37, 785-789.

(65) Becke, A. D. Density-functional Thermochemistry. III. The Role of Exact Exchange. $J$. Chem. Phys. 1993, 98, 5648-5652. 
(66) Perdew, J. P.; Burke, K.; Ernzerhof, M. Generalized Gradient Approximation Made Simple. Phys. Rev. Lett. 1996, 77, 3865.

(67) Perdew, J. P. Density-Functional Approximation for the Correlation Energy of the Inhomogeneous Electron Gas. Phys. Rev. B 1986, 33, 8822-8824.

(68) Becke, A. D. Density-Functional Exchange-Energy Approximation with Correct Asymptotic Behavior. Phys. Rev. A 1988, 38, 3098-3100.

(69) Pauling, L. The Nature of the Chemical Bond. III. The Transition from One Extreme Bond Type to Another. J. Am. Chem. Soc. 1932, 54, 988-1003.

(70) Pauling, L. The Nature of the Chemical Bond. IV. The Energy of Single Bonds and the Relative Electronegativity of Atoms. J. Am. Chem. Soc. 1932, 54, 3570-3582.

(71) Varma, C. M.; Wilson, A. J. Systematics of the Binding Energy of Oxygen and Hydrogen on Transition-Metal Surfaces. I. Phys. Rev. B 1980, 22, 3795-3804.

(72) Nielsen, M. T.; Moltved, K. A.; Kepp, K. P. Electron Transfer of Hydrated Transition-Metal Ions and the Electronic State of Co3+(Aq). Inorg. Chem. 2018, 57, 7914-7924.

(73) Schmidt, P. S.; Thygesen, K. S. Benchmark Database of Transition Metal Surface and Adsorption Energies from Many-Body Perturbation Theory. J. Phys. Chem. C 2018, 122, $4381-4390$.

(74) Carter, E. A.; Goddard, W. A. Relationships between Bond Energies in Coordinatively Unsaturated and Coordinatively Saturated Transition-Metal Complexes: A Quantitative Guide for Single, Double, and Triple Bonds. J. Phys. Chem. 1988, 92, 5679-5683. 
Table of Content Graphic

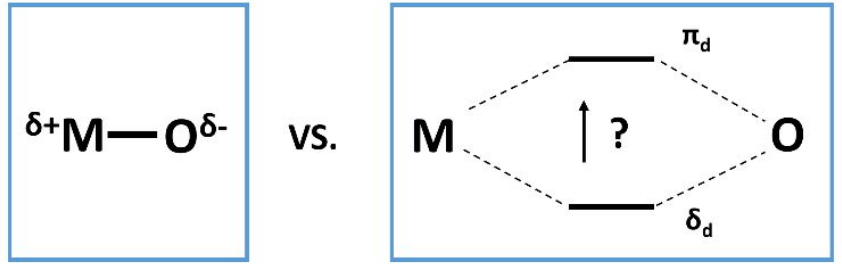

Electronegativity or d-antibonding effect?

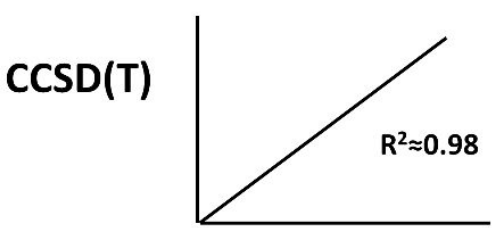

Experiment

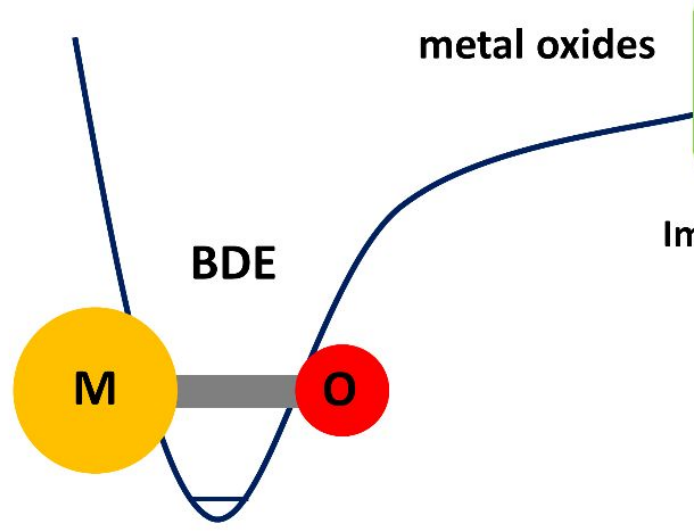

Sc Ti V Cr Mn Fe Co Ni Cu Zn Y Zr Nb Mo Tc Ru Rh Pd Ag Cd La Hf Ta W Re Os Ir Pt Au Hg

Importance of local M-O bond vs. metal surface

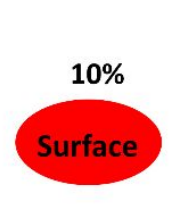

$90 \%$

\section{Local M-O bond}




\section{Figure legends}

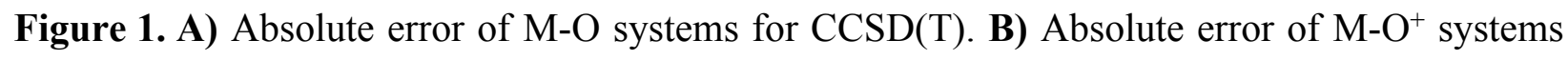
for $\operatorname{CCSD}(\mathrm{T})$. A threshold of $30 \mathrm{~kJ} / \mathrm{mol}$ (red color) is used to identify difficult cases, values are tabulated in Table S15. C) Linear relation between experimental (Table 1) and CCSD(T)computed BDEs (Table S12). D) Relation between experimental ionization potentials (IP) and CCSD(T)-computed IPs (Table S16).

Figure 2. A) Experimental (Table 1) and $\operatorname{CCSD}(\mathrm{T})$ computed BDEs (Table S12) for the $3 \mathrm{~d}$ transition metaloxides. B) For the $4 \mathrm{~d}$ transition metaloxides. C) For the $5 \mathrm{~d}$ transition metaloxides. D) For the cationic $3 \mathrm{~d}$ transition metaloxides. E) For the cationic $4 \mathrm{~d}$ transition metaloxides. F) For the cationic $5 \mathrm{~d}$ transition metaloxides.

Figure 3. Metal charge, oxygen charge, spin density on oxygen and spin density on the metal, from natural population analysis using B3LYP/aug-cc-pV5Z/def2-QZVPP (tabulated values in Table S17). A) Neutral 3d metal oxides. B) Cationic 3d metal oxides. C) Neutral 4d metal oxides. D) Cationic $4 \mathrm{~d}$ metal oxides. E) Neutral $5 \mathrm{~d}$ metal oxides. F) Cationic $5 \mathrm{~d}$ metal oxides.

Figure 4. A) Linear relation between experimental BDE (Table 1) and Mulliken electronegativity (Table S16) of the transition metals. B) Relation between CCSD(T)-computed BDEs (Table S12) and Mulliken electronegativity. C) Relation between experimental M-O BDE and oxophilicity ${ }^{15}$ (Table S16). D) Relation between CCSD(T)-computed BDE and oxophilicity. 
Figure 5. A) Linear relation between experimental M-O BDEs (Table 1) and previously computed random phase approximation (RPA) adsorption energies. ${ }^{73}$ B) Relation between experimental BDEs and previously computed PBE-computed adsorption energies ${ }^{73}$. C) Relation between PBEcomputed BDEs (this work, Table S12) and previously computed PBE-computed adsorption energies $^{73}$ D). Relation between CCSD(T)-computed BDEs (this work, Table S12) and RPAcomputed adsorption energies ${ }^{73}$. 
A
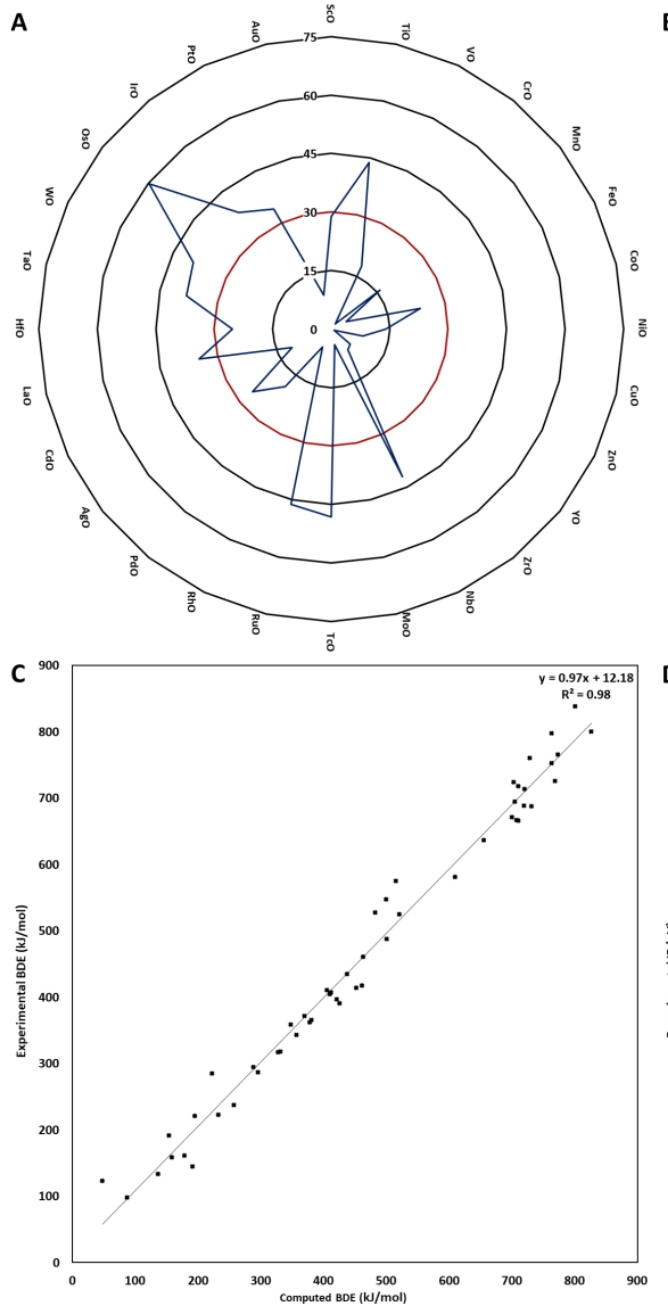

B
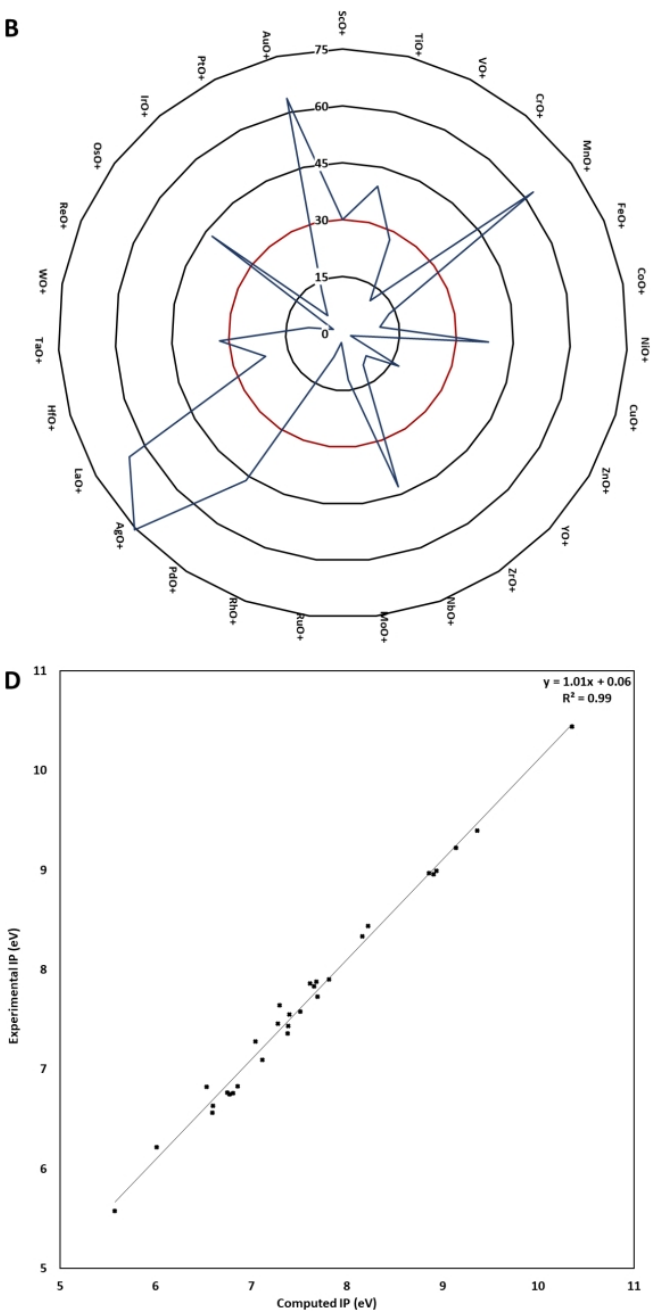

Figure 1

$600 \times 600 \mathrm{~mm}(96 \times 96 \mathrm{DPI})$ 

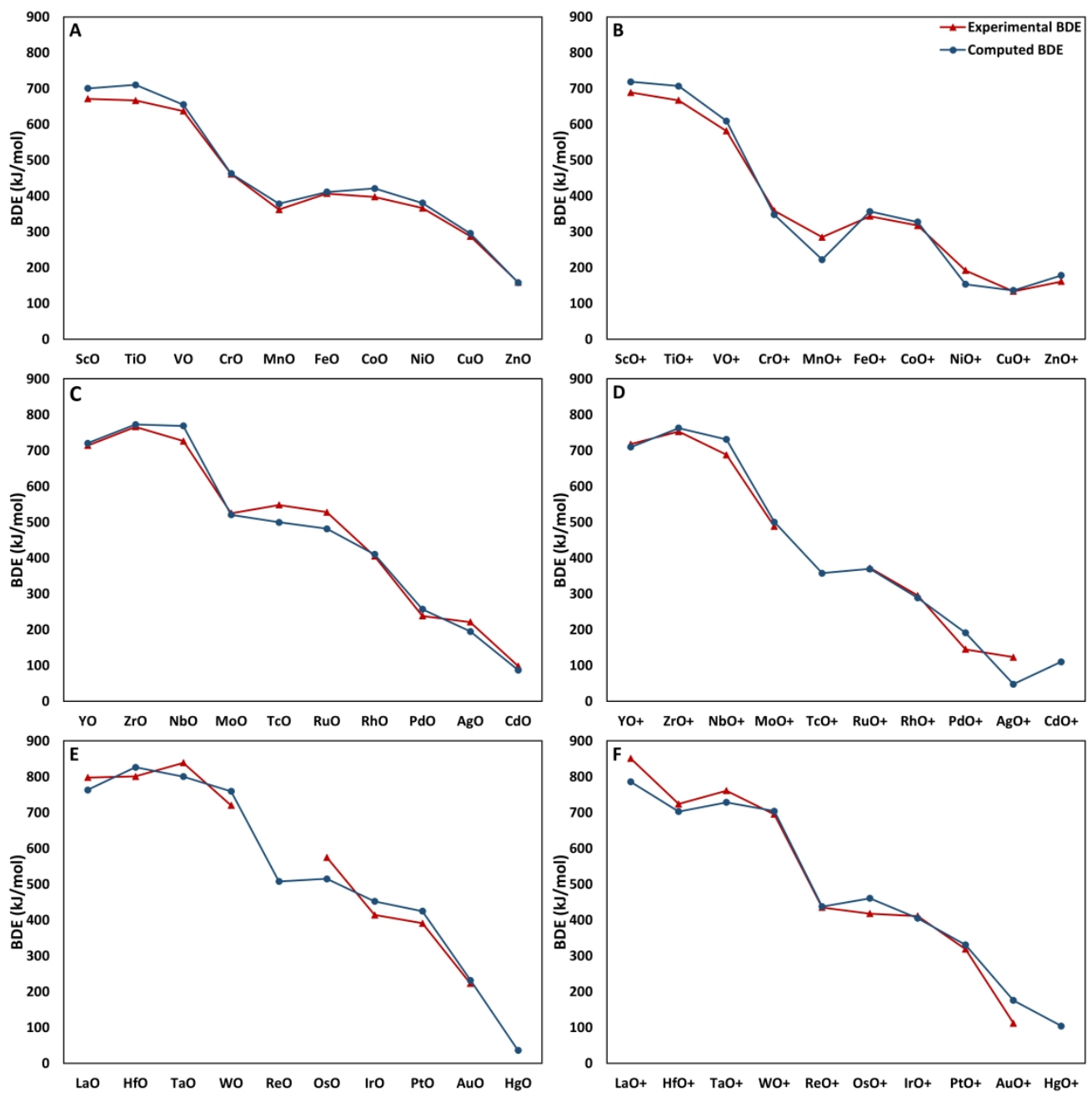

Figure 2

$299 \times 299 \mathrm{~mm}(300 \times 300$ DPI $)$ 

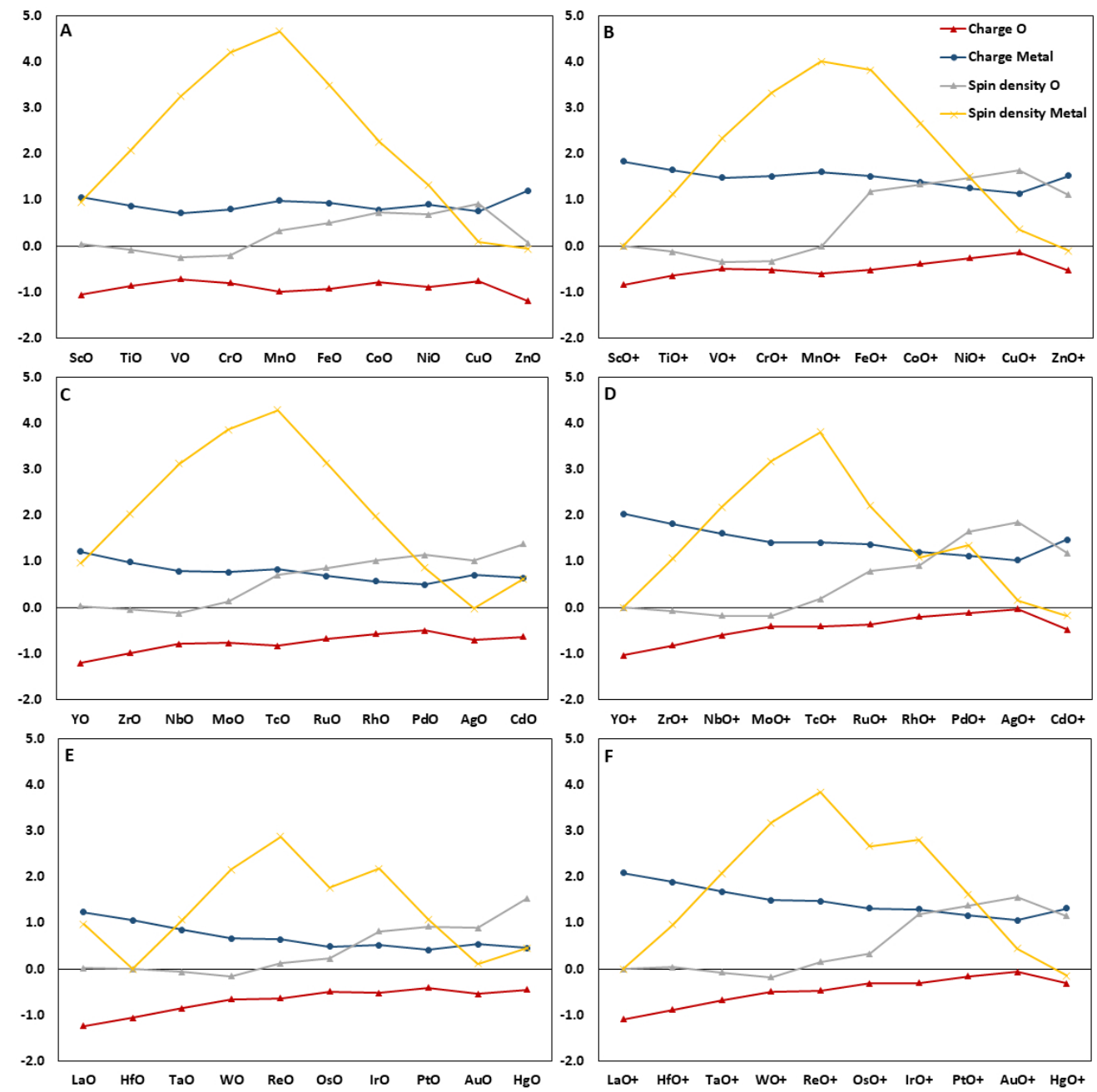

Figure 3

$300 \times 300 \mathrm{~mm}(96 \times 96 \mathrm{DPI})$ 

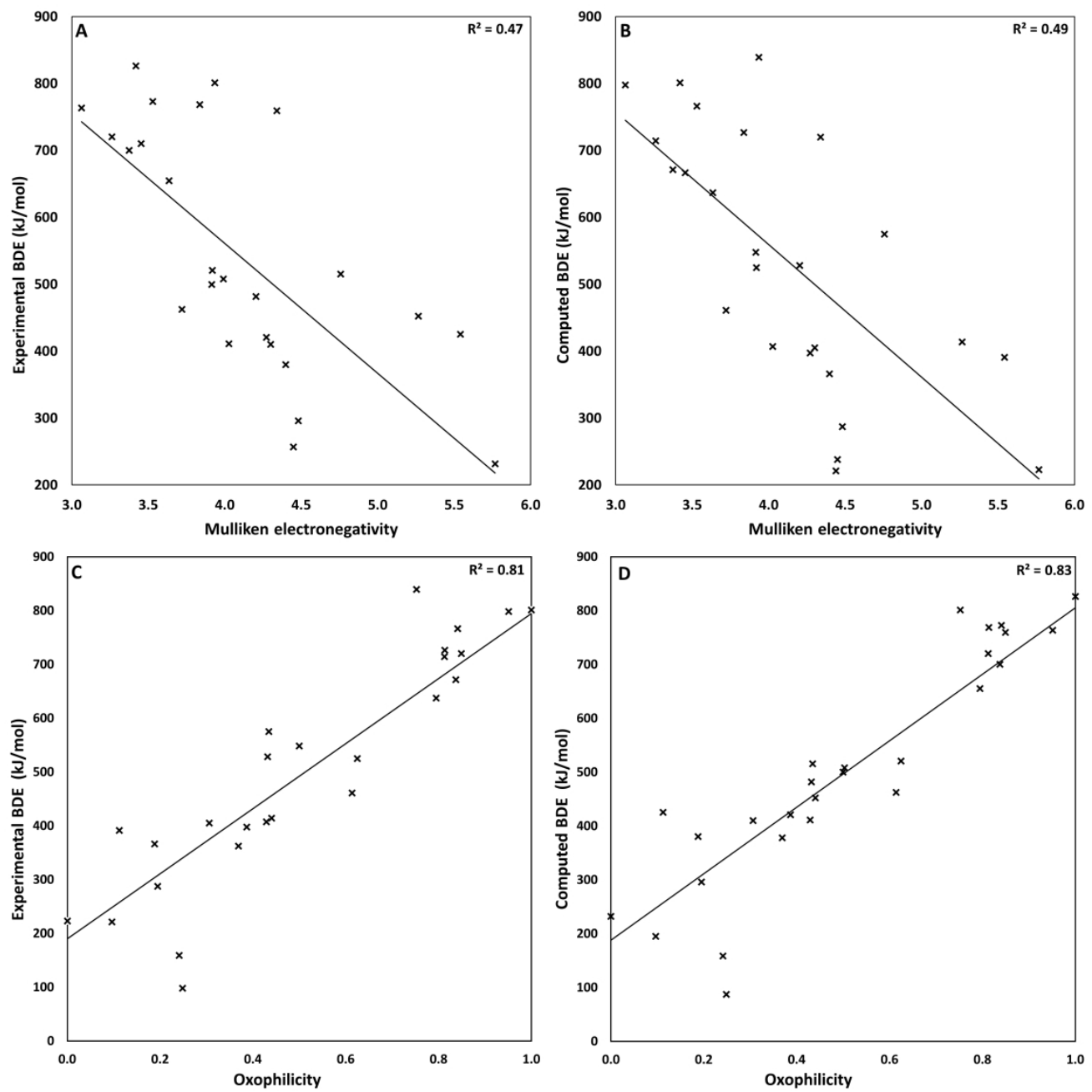

Figure 4

$299 \times 299 \mathrm{~mm}(300 \times 300$ DPI $)$ 

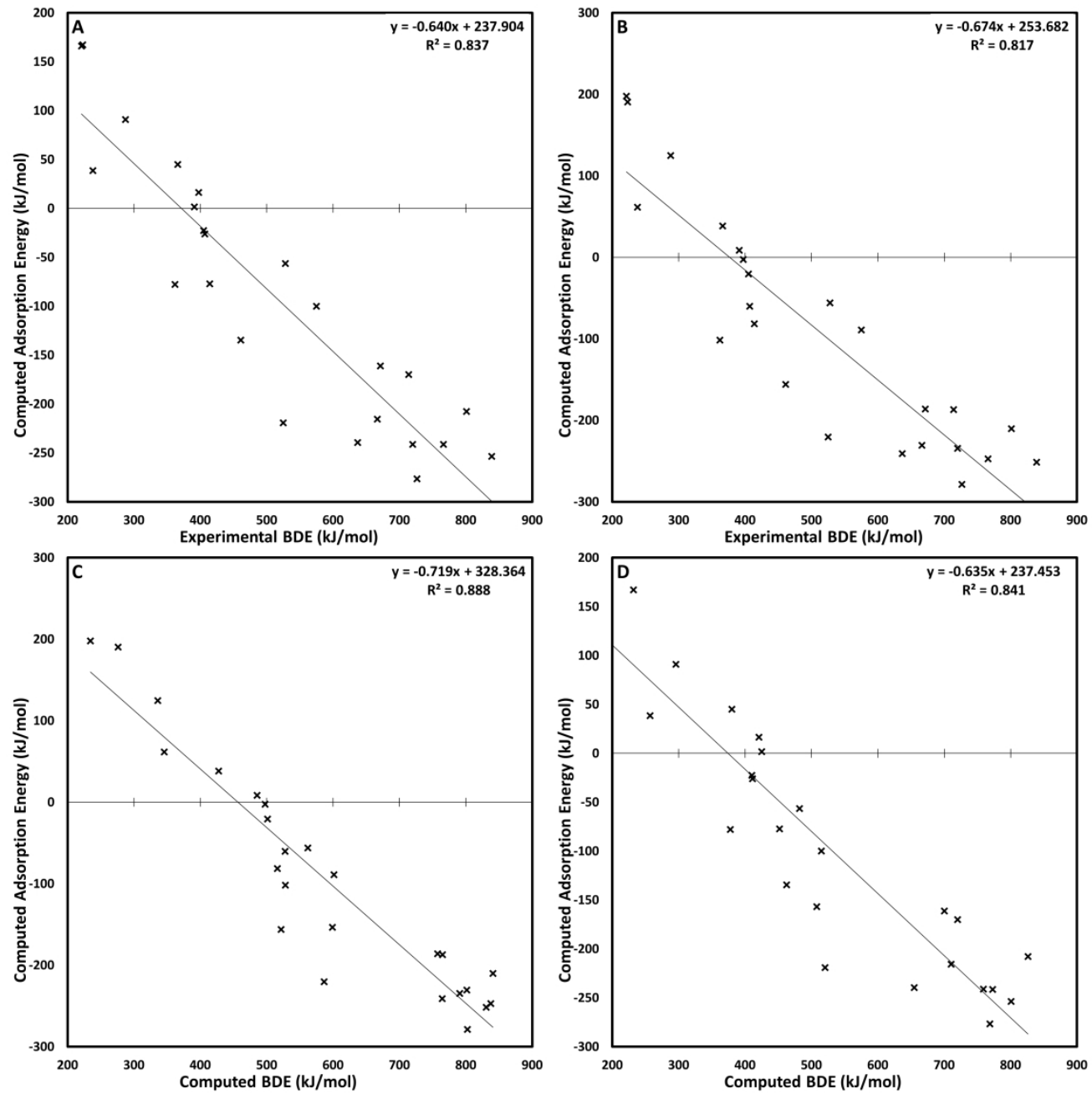

Figure 5

$299 \times 299 \mathrm{~mm}(300 \times 300 \mathrm{DPI})$ 


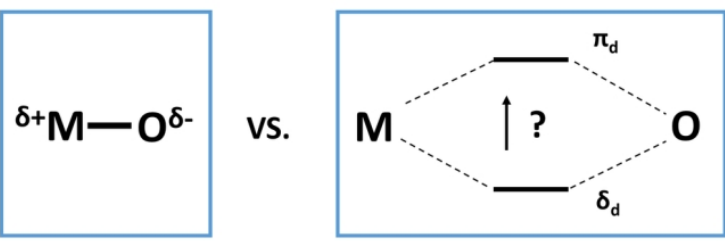

Electronegativity or d-antibonding effect?

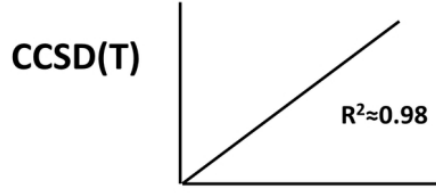

Experiment

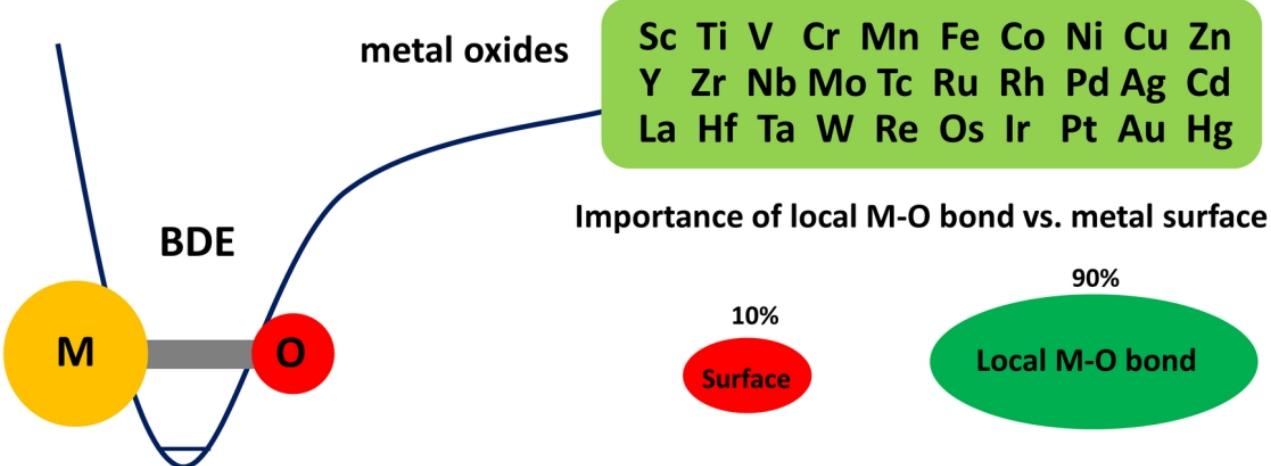

TOC graphic

$150 \times 88 \mathrm{~mm}(300 \times 300 \mathrm{DPI})$ 